JURNAL KEBIDANAN

Vol 6, No 3, Juli 2020 : 376-382

\title{
PERSEPSI PETUGAS GIZI DALAM PEMANTAUAN STATUS GIZI BALITA DENGAN MENGGUNAKAN WEBSITE IPOSYANDU
}

\author{
Ari Indra Susanti ${ }^{1}$, Didah², Atriany Nilam Sari ${ }^{3}$, Dani Ferdian ${ }^{4}$, Fedri Ruluwedrata Rinawan ${ }^{5}$ \\ 1Departemen IImu Kesehatan Masyarakat, FK Unpad \\ email:Ukhti3in1@yahoo.com \\ 2Departemen IImu Kesehatan Masyarakat, FK Unpad \\ email : didahramdani@gmail.com \\ 32Departemen IImu Kesehatan Masyarakat, FK Unpad \\ email : atrianynilamsari@gmail.com \\ ${ }^{4}$ Departemen IImu Kesehatan Masyarakat, FK Unpad \\ email: ferdian.dani@yahoo.com \\ ${ }^{5}$ Departemen IImu Kesehatan Masyarakat, FK Unpad \\ email: f.rinawan@gmail.com
}

\begin{abstract}
Backgroud:The development of technology that is developing rapidly so at this time all information, especially about health using the internet. This can help the nutrition officer task in monitoring the nutritional status of children under five by using the website.

The purpose of this study was to determine the perception of nutrition officers in monitoring the nutritional status of infants by using the iPosyandu website.

The research method uses descriptive cross sectional approach. This research was conducted in October until December 2019 with 50 nutrition workers in PKM in the Karawang regency working area. The sampling technique uses total sampling. Data analysis used to univariate variable in the form of a frequency distribution table.

The results showed that nutrition workers had a perception that the ease of accessing information through the website was $50 \%$. Then for the contents of the website is complete and clear by $45 \%$, and there is information and privacy in finding information related to iPosyandu by $32 \%$, and the accuracy of the selection of font size in the website display by $55 \%$.

The conclusion in this study is the perception of nutrition officers towards the website mostly agree on the site, content, information, and appearance of the iPosyandu website.

Sugestion based on the results of this study that the iPosyandu website can provide important information to nutrition workers to facilitate monitoring of the implementation of nutritional status monitoring in the work area of each health center so that it can be quickly and appropriately handled if there are cases of malnutrition in children under five in their region.
\end{abstract}

Keyword: Perception, Nutritionist, iPosyandu Website

\section{ABSTRAK}

Latar Belakang Seiring dengan perkembangan teknologi yang berkembang dengan pesat maka saat ini semua informasi terutama tentang kesehatan menggunakan internet. Hal tersebut, dapat membantu tugas petugas gizi dalam melakukan pemantuan status gizi balita dengan menggunakan website.

Tujuan penelitian ini untuk mengetahui persepsi petugas gizi dalam pemantauan status gizi balita dengan menggunakan website iPosyandu.

Metode Penelitian menggunakan deskriptif pendekatan cross sectional. Penelitian ini dilakukan pada bulan Oktober s.d Desember 2019 pada petugas gizi di PKM wilayah kerja Kabupaten Karawang sebanyak 50 orang. Teknik pengambilan sampel dengan menggunakan total sampling. Analisis data menggunakan univariat yang disajikan dalam bentuk tabel distribusi frekuensi.

Hasil Penelitian didapatkan bahwa petugas gizi memiliki persepsi bahwa kemudahan dalam mengakses informasi melalui website sebesar $50 \%$. Kemudian untuk isi situs web sudah lengkap dan jelas sebesar $45 \%$, dan terdapat informasi dan privasi dalam menemukan informasi terkait iPosyandu sebesar 32\%, serta ketepatan pemilihan ukuran huruf dalam tampilan website sebesar $55 \%$. 
Simpulan dalam penelitian ini bahwa persepsi petugas gizi terhadap website sebagian besar setuju terhadap situs, isi, informasi, dan tampilan situs website iPosyandu.

Saran berdasarkan hasil penelitian ini bahwa website iPosyandu dapat memberikan informasi penting kepada petugas gizi untuk memudahkan pemantauan pelaksanaan pemantaun status gizi di wilayah kerja Puskesmas masing-masing agar bisa cepat dan tepat di tangani apabila terdapat kasus-kasus penyimpangan gizi pada balita di wilayah nya.

Kata Kunci: Persepsi, Petugas Gizi, Website iPosyandu

\section{PENDAHULUAN}

Stunting atau tinggi badan rendah berdasarkan usia adalah masa pertumbuhan yang disebabkan oleh ketidakcukupan asupan nutrisi dakan jangka panjang ditambah dengan kasus penyakit yang sering, terutama selama 1000 hari kehidupan. Di Indonesia, 37,2\% anak-anak yang berusia kurang dari lima tahun mengalami stunting. Malnutrisi selama 2 tahun pertama kehidupan dapat menyebabkan mortalitas dan morbiditas.(ChiritaEmandi et al., 2016)

Saat ini sudah berbagai upaya yang dilakukan dalam mengatasi terjadinya stunting baik secara spesifik maupun sensitif, namun nyatanya belum terjadi penurunan yang signifikan, selain itu dalam memperoleh informasi data mengenai pertumbuhan dan perkembangan anak yang masih diragukan. Seperti halnya, kader menemukan kesulitan yaitu terlambatnya pemberian laporan mengenai pengukuran status gizi bayi dan balita, disebabkan karena waktu yang lama antara pencatatan dan pemindahan data ke buku laporan Puskesmas.(Susanti et al., 2019)

Permasalahan ini dapat berdampak pada data yang sulit didapat ataupun data menjadi tidak valid, hal ini berujung pada petugas kesehatan khususnya petugas gizi. Petugas gizi akan terasa sulit untuk melakukan rekapitulasi data serta intervensi yang akan dilakukan. Upaya mengatasi permasalahan tersebut ialah melakukan inovasi teknologi, berbasis website. (Dikti) Pencatatan yang dilakukan oleh kader melalui aplikasi kemudian akan tersambung ke website. Website tersebut menampilkan berbagai fitur teutama mengenai pertumbuhan dan perkembangan anak terkini.(Aziz, 2016)

Pemantauan Pertumbuhan, Perkembangan, dan Gangguan Tumbuh Kembang Anak merupakan acuan bagi tenaga kesehatan yang bekerja pada fasilitas pelayanan kesehatan dasar/primer, kelompok profesi, tenaga pendidik, petugas lapangan Keluarga Berencana, petugas sosial yang terkait dengan pembinaan tumbuh kembang anak, organisasi profesi dan pemangku kepentingan terkait pertumbuhan, perkembangan, dan gangguan tumbuh kembang anak.(Mujiastuti et al., 2018)

Penelitian ini bertujuan untuk mengetahui persepsi petugas gizi dalam pemantauan status gizi balita dengan menggunakan website iPosyandu.

\section{METODE PENELITIAN}

Desain penelitian dengan menggunakan deskriptif pendekatan cross sectional. Penelitian ini dilakukan pada bulan Oktober s.d Desember 2019 pada petugas gizi di PKM wilayah kerja Kabupaten Karawang sebanyak 50 orang. Kriteria inklusi pada penelitian ini adalah petugas gizi di wilayah kerja Dinas Kesehatan Karawang yang hadir saat pelatihan tentang website iPosyandu. Sedangkan kriteria eksklusi adalah petugas gizi yang tidak bersedia mengisi lembar informed consent dan yang tidak mengisi kuesioner dengan lengkap. Teknik pengambilan sampel dengan menggunakan total sampling. Pengambilan data dilakukan pada saat akhir pelatihan petugas gizi tentang website iPosyandu dengan memberikan kuesioner tentang persepsi petugas gizi dalam menggunakan website iPosyandu kepada petugas gizi. Kuesioner tersebut berdasarkan dari artikel dengan judul Developing and validating an instrument for measuring userperceived web quality. Information \& management.(Aladwani and Palvia, 2002). Analisis data menggunakan univariat yang disajikan dalam bentuk tabel distribusi frekuensi. Penelitian ini mendapatkan ijin etik penelitian No. 1456/UN6.KEP/EC/2019 dari Komisi Etik Penelitian Universitas Padjadjaran. 


\section{HASIL PENELITIAN}

Tabel 1.

Persepsi Petugas Gizi tentang Situs Website Aplikasi iPosyandu

\begin{tabular}{|c|c|c|c|c|c|c|c|c|c|c|c|c|c|c|}
\hline \multirow{3}{*}{ Indikator Persepsi } & \multicolumn{14}{|c|}{ Skala } \\
\hline & \multicolumn{2}{|c|}{$\begin{array}{l}\text { Sangat } \\
\text { Tidak } \\
\text { Setuju }\end{array}$} & \multicolumn{2}{|c|}{$\begin{array}{l}\text { Tidak } \\
\text { Setuju }\end{array}$} & \multicolumn{2}{|c|}{$\begin{array}{l}\text { Agak } \\
\text { Tidak } \\
\text { Setuju }\end{array}$} & \multicolumn{2}{|c|}{ Netral } & \multicolumn{2}{|c|}{$\begin{array}{l}\text { Agak } \\
\text { Setuju }\end{array}$} & \multicolumn{2}{|c|}{ Setuju } & \multicolumn{2}{|c|}{$\begin{array}{l}\text { Sangat } \\
\text { Setuju }\end{array}$} \\
\hline & $\mathrm{n}$ & $\%$ & $\mathrm{n}$ & $\%$ & $n$ & $\%$ & $\mathrm{n}$ & $\%$ & $\mathrm{n}$ & $\%$ & $\mathrm{n}$ & $\%$ & $\mathrm{n}$ & $\%$ \\
\hline $\begin{array}{l}\text { Kemudahan mengakses website } \\
\text { dengan menggunakan berbagai jenis } \\
\text { browser }\end{array}$ & 0 & 0 & 0 & 0 & 2 & 5 & 7 & 16 & 2 & 27 & 14 & 32 & 9 & 20 \\
\hline $\begin{array}{l}\text { Kemudahan dalam menjelajahi situs } \\
\text { web (browsing) }\end{array}$ & 0 & 0 & 0 & 0 & 1 & 2 & 9 & 20 & 12 & 27 & 14 & 32 & 8 & 18 \\
\hline $\begin{array}{l}\text { Memiliki fasilitas pencarian yang } \\
\text { memadai }\end{array}$ & 0 & 0 & 0 & 0 & 1 & 2 & 9 & 18 & 9 & 20 & 19 & 43 & 6 & 14 \\
\hline $\begin{array}{l}\text { Kemudahan dalam mengakses } \\
\text { informasi melalui website }\end{array}$ & 0 & 0 & 0 & 0 & 1 & 2 & 8 & 18 & 7 & 16 & 22 & 50 & 6 & 14 \\
\hline $\begin{array}{l}\text { Memiliki tautan (hyperlink) yang valid } \\
\text { Dapat dipersonalisasi atau }\end{array}$ & 0 & 0 & 0 & 0 & 1 & 2 & 10 & 3 & 8 & 19 & 21 & 49 & 3 & 7 \\
\hline $\begin{array}{l}\text { disesuaikan untuk memenuhi } \\
\text { kebutuhan seseorang }\end{array}$ & 0 & 0 & 0 & 0 & 2 & 5 & 13 & 30 & 7 & 16 & 20 & 45 & 2 & 5 \\
\hline $\begin{array}{l}\text { Halaman web dapat di buka dengan } \\
\text { cepat di situs web (loading cepat) }\end{array}$ & 0 & 0 & 0 & 0 & 1 & 2 & 14 & 32 & 10 & 23 & 17 & 39 & 2 & 5 \\
\hline Memiliki banyak fitur interaktif & 0 & 0 & 0 & 0 & 2 & 5 & 14 & 32 & 11 & 25 & 17 & 39 & 0 & 0 \\
\hline $\begin{array}{l}\text { Situs web mudah diakses (mempunyai } \\
\text { nama yang dikenal secara luas) }\end{array}$ & 0 & 0 & 0 & 0 & 2 & 5 & 12 & 27 & 12 & 27 & 18 & 41 & 0 & 0 \\
\hline
\end{tabular}

Berdasarkan tabel 1. di atas, didapatkan hasil bahwa persepsi petugas gizi tentang situs website aplikasi iPosyandu sebagian besar setuju, meliputi Kemudahan mengakses website dengan menggunakan berbagai jenis browser sebesar 32\%, kemudahan dalam menjelajahi situs web (browsing) sebesar $32 \%$, memiliki fasilitas pencarian yang memadai sebesar $43 \%$, kemudahan dalam mengakses informasi melalui website sebesar $50 \%$, memiliki tautan (hyperlink) yang valid sebesar 49\%, Dapat dipersonalisasi atau disesuaikan untuk memenuhi kebutuhan seseorang sebesar $45 \%$, Halaman web dapat di buka dengan cepat di situs web (loading cepat) sebesar 39\%, Memiliki banyak fitur interaktif sebesar 39\%, dan Situs web mudah diakses (mempunyai nama yang dikenal secara luas) sebesar $41 \%$.

Tabel 2.

Persepsi Petugas Gizi mengenai Isi Situs Website

\begin{tabular}{|c|c|c|c|c|c|c|c|c|c|c|c|c|c|c|}
\hline \multirow{3}{*}{ Indikator Persepsi } & \multicolumn{14}{|c|}{ Skala } \\
\hline & \multicolumn{2}{|c|}{$\begin{array}{c}\text { Sangat } \\
\text { Tidak } \\
\text { Setuju }\end{array}$} & \multicolumn{2}{|c|}{$\begin{array}{l}\text { Tidak } \\
\text { Setuju }\end{array}$} & \multicolumn{2}{|c|}{$\begin{array}{l}\text { Agak } \\
\text { Tidak } \\
\text { Setuju }\end{array}$} & \multicolumn{2}{|c|}{ Netral } & \multicolumn{2}{|c|}{$\begin{array}{l}\text { Agak } \\
\text { Setuju }\end{array}$} & \multicolumn{2}{|c|}{ Setuju } & \multicolumn{2}{|c|}{$\begin{array}{l}\text { Sangat } \\
\text { Setuju }\end{array}$} \\
\hline & $\mathrm{n}$ & $\%$ & $\mathrm{~N}$ & $\%$ & $\mathrm{n}$ & $\%$ & $\mathrm{n}$ & $\%$ & $\mathrm{n}$ & $\%$ & $\mathrm{n}$ & $\%$ & $\mathrm{n}$ & $\%$ \\
\hline $\begin{array}{l}\text { Isi situs web bermanfaat untuk } \\
\text { pencatatan dan pelaporan UKGS }\end{array}$ & 0 & 0 & 0 & 0 & 1 & 2 & 3 & 7 & 12 & 27 & 19 & 43 & 9 & 20 \\
\hline Isi situs web sudah lengkap & 0 & 0 & 0 & 0 & 2 & 5 & 13 & 30 & 7 & 16 & 20 & 45 & 2 & 5 \\
\hline Isi situs web jelas & 0 & 0 & 0 & 0 & 1 & 2 & 8 & 18 & 13 & 30 & 20 & 45 & 2 & 5 \\
\hline $\begin{array}{l}\text { Isi situs web sesuai dengan } \\
\text { kebutuhan saat ini }\end{array}$ & 0 & 0 & 0 & 0 & 0 & 0 & 12 & 27 & 11 & 25 & 19 & 43 & 2 & 5 \\
\hline Isi situs web singkat & 0 & 0 & 0 & 0 & 0 & 0 & 12 & 18 & 13 & 30 & 18 & 41 & 1 & 2 \\
\hline Isi situs web akurat & 0 & 0 & 0 & 0 & 2 & 5 & 8 & 18 & 15 & 34 & 17 & 39 & 2 & 5 \\
\hline
\end{tabular}


Berdasarkan tabel 2. di atas, didapatkan hasil bahwa persepsi petugas gizi mengenai isi situs website sebagian besar setuju, yaitu situs web bermanfaat untuk pencatatan dan pelaporan UKGS sebesar $43 \%$, isi situs web sudah lengkap sebesar
$45 \%$, isi situs web jelas sebesar $45 \%$, isi situs web sesuai dengan kebutuhan saat ini sebesar $43 \%$, isi situs web singkat sebesar $41 \%$, dan isi situs web akurat.

Tabel 3.

Persepsi Petugas Gizi mengenai Informasi dalam Situs Webiste

\begin{tabular}{|c|c|c|c|c|c|c|c|c|c|c|c|c|c|c|}
\hline \multirow{3}{*}{ Indikator Persepsi } & \multicolumn{14}{|c|}{ Skala } \\
\hline & \multicolumn{2}{|c|}{$\begin{array}{l}\text { Sangat } \\
\text { Tidak } \\
\text { Setuju }\end{array}$} & \multicolumn{2}{|c|}{$\begin{array}{l}\text { Tidak } \\
\text { Setuju }\end{array}$} & \multicolumn{2}{|c|}{$\begin{array}{l}\text { Agak } \\
\text { Tidak } \\
\text { Setuju }\end{array}$} & \multicolumn{2}{|c|}{ Netral } & \multicolumn{2}{|c|}{$\begin{array}{l}\text { Agak } \\
\text { Setuju }\end{array}$} & \multicolumn{2}{|c|}{ Setuju } & \multicolumn{2}{|c|}{$\begin{array}{l}\text { Sangat } \\
\text { Setuju }\end{array}$} \\
\hline & $n$ & $\%$ & $\mathrm{~N}$ & $\%$ & $n$ & $\%$ & $n$ & $\%$ & $n$ & $\%$ & $n$ & $\%$ & $n$ & $\%$ \\
\hline Adanya informasi kontak & 0 & 0 & 0 & 0 & 1 & 2 & 10 & 23 & 12 & 27 & 8 & 30 & 9 & 18 \\
\hline $\begin{array}{l}\text { Adanya informasi umum tentang } \\
\text { iPosyandu }\end{array}$ & 0 & 0 & 0 & 0 & 1 & 2 & 4 & 9 & 18 & 41 & 9 & 27 & 8 & 20 \\
\hline $\begin{array}{l}\text { Adanya informasi tentang kegiatan } \\
\text { iPosyandu }\end{array}$ & 0 & 0 & 0 & 0 & 1 & 2 & 7 & 16 & 12 & 27 & 10 & 32 & 10 & 23 \\
\hline $\begin{array}{l}\text { Adanya privasi dalam menemukan } \\
\text { informasi yang terkait dengan } \\
\text { iPosyandu }\end{array}$ & 0 & 0 & 0 & 0 & 1 & 2 & 7 & 16 & 14 & 32 & 8 & 32 & 8 & 18 \\
\hline $\begin{array}{l}\text { Adanya informasi yang terkait } \\
\text { dengan pelayanan pelanggan }\end{array}$ & 0 & 0 & 0 & 0 & 1 & 2 & 8 & 18 & 18 & 41 & 4 & 30 & 4 & 9 \\
\hline
\end{tabular}

Berdasarkan tabel 3 di atas, didapatkan bahwa persepsi petugas gizi mengenai informasi dalam situs website sebagian besar setuju, meliputi informasi kontak sebesar 30\%, informasi umum tentang iPosyandu sebesar 27\%, informasi tentang kegiatan iPosyandu sebesar $32 \%$, privasi dalam menemukan informasi yang terkait dengan iPosyandu sebesar 32\%, dan informasi yang terkait dengan pelayanan pelanggan sebesar $30 \%$.

Tabel 4.

Persepsi Petugas Gizi terkait Tampilan Situs Website

\begin{tabular}{|c|c|c|c|c|c|c|c|c|c|c|c|c|c|c|}
\hline \multirow{3}{*}{ Indikator Persepsi } & \multicolumn{14}{|c|}{ Skala } \\
\hline & \multicolumn{2}{|c|}{$\begin{array}{c}\text { Sangat } \\
\text { Tidak } \\
\text { Setuju }\end{array}$} & \multicolumn{2}{|c|}{$\begin{array}{l}\text { Tidak } \\
\text { Setuju }\end{array}$} & \multicolumn{2}{|c|}{$\begin{array}{l}\text { Agak } \\
\text { Tidak } \\
\text { Setuju }\end{array}$} & \multicolumn{2}{|c|}{ Netral } & \multicolumn{2}{|c|}{$\begin{array}{l}\text { Agak } \\
\text { Setuju }\end{array}$} & \multicolumn{2}{|c|}{ Setuju } & \multicolumn{2}{|c|}{$\begin{array}{l}\text { Sangat } \\
\text { Setuju }\end{array}$} \\
\hline & $\mathrm{n}$ & $\%$ & $\mathrm{~N}$ & $\%$ & $\mathrm{n}$ & $\%$ & $\mathrm{n}$ & $\%$ & $\mathrm{n}$ & $\%$ & $\mathrm{n}$ & $\%$ & $\mathrm{n}$ & $\%$ \\
\hline Situs web terlihat menarik & 0 & 0 & 0 & 0 & 2 & 5 & 8 & 18 & 9 & 20 & 18 & 41 & 7 & 16 \\
\hline Situs web terlihat terorganisir & 0 & 0 & 0 & 0 & 1 & 2 & 8 & 18 & 9 & 20 & 19 & 43 & 7 & 16 \\
\hline Ketepatan pemilihan ukuran huruf & 0 & 0 & 0 & 0 & 0 & 0 & 6 & 14 & 9 & 20 & 24 & 55 & 5 & 11 \\
\hline Ketepatan pemilihan warna & 0 & 0 & 0 & 0 & 2 & 5 & 6 & 14 & 11 & 25 & 21 & 48 & 5 & 9 \\
\hline $\begin{array}{l}\text { Ketepatan menggunakan fitur } \\
\text { multimedia }\end{array}$ & 0 & 0 & 0 & 0 & 2 & 5 & 9 & 20 & 9 & 20 & 20 & 45 & 4 & 9 \\
\hline
\end{tabular}

Berdasarkan tabel 4. di atas didapatkan bahwa persepsi petugas gizi terkait tampilan situs website sebagian besar setuju, meliputi situs web terlihat menarik sebesar $41 \%$, situs web terlihat terorganisir sebesar $43 \%$, ketepatan pemilihan ukuran huruf sebesar $55 \%$, ketepatan pemilihan warna sebesar $48 \%$, dan ketepatan menggunakan fitur multimedia sebesar $45 \%$.

\section{PEMBAHASAN}

Berdasarkan tabel 1. di atas, didapatkan hasil bahwa persepsi petugas gizi tentang situs website aplikasi iPosyandu sebagian besar setuju, meliputi Kemudahan mengakses website dengan menggunakan berbagai jenis browser sebesar $32 \%$, kemudahan dalam menjelajahi situs web (browsing) sebesar $32 \%$, memiliki fasilitas pencarian yang 
memadai sebesar 43\%, kemudahan dalam mengakses informasi melalui website sebesar $50 \%$, memiliki tautan (hyperlink) yang valid sebesar $49 \%$, Dapat dipersonalisasi atau disesuaikan untuk memenuhi kebutuhan seseorang sebesar $45 \%$, Halaman web dapat di buka dengan cepat di situs web (loading cepat) sebesar 39\%, Memiliki banyak fitur interaktif sebesar 39\%, dan Situs web mudah diakses (mempunyai nama yang dikenal secara luas) sebesar $41 \%$.

Berdasarkan segi kualitas sistem, basis website memiliki tingkat efektivitas yang sama dengan basis dekstop dibandingkan basis buku, begitu juga dengan segi kualitas informasi, dan kepuasan pengguna.(Darely and lqbal, 2019)

Hasil tersebut sejalan dengan hasil penelitian yang dilakukan di Semarang bahwa pemetaan dari status gizi balita yang terdapat di wilayah Kota Semarang dengan menggunakan website dan google map yang mudah digunakan untuk melihat cakupan status gizi balita. Selain itu juga, sebagai pendukung pengambilan keputusan bagi pengelola program gizi bidang Kesga untuk mendukung tercapainya MGDs 2015.(Setyowati and Astuti, 2015)

Berdasarkan tabel 2. di atas, didapatkan hasil bahwa persepsi petugas gizi mengenai isi situs website sebagian besar setuju, yaitu situs web bermanfaat untuk pencatatan dan pelaporan UKGS sebesar $43 \%$, isi situs web sudah lengkap sebesar
$45 \%$, isi situs web jelas sebesar $45 \%$, isi situs web sesuai dengan kebutuhan saat ini sebesar $43 \%$, isi situs web singkat sebesar $41 \%$, dan isi situs web akurat.

Penilaian kualitas situs web dianggap sebagai masalah dalam mengukur kepuasan pengguna, untuk menganalisis persepsi dan preferensi pengguna. Dengan proliferasi situs web dan internet komersial yang diinvestasikan di dalamnya, penilaian kualitas situs web telah berkembang sebagai kegiatan penting. Situs web modern menghadirkan beragam fitur, kompleksitas struktur, dan pluralitas layanan yang ditawarkan secara signifikan. Seperti dalam kasus semua sistem informasi, evaluasi merupakan aspek pengembangan dan operasinya yang dapat berkontribusi untuk memaksimalkan eksploitasi sumber daya yang diinvestasikan (Adelman, 1991). Selain itu, penilaian situs web juga dapat secara signifikan berkontribusi pada pengembangan mereka yang melayani kebutuhan pengguna dan memenuhi harapan pengguna hingga batas maksimum yang dimungkinkan.(Anestis et al., 2006)

Pada tampilan website iPosyandu terdapat data yang meliputi: total Posyandu, total bayi dan balita dari seluruh Posyandu, total ibu hamil, total Wanita Usia Subur (WUS), dan total Pasangan Usia Subur (PUS) serta grafik keadaan bayi dan balita di seluruh Posyandu.

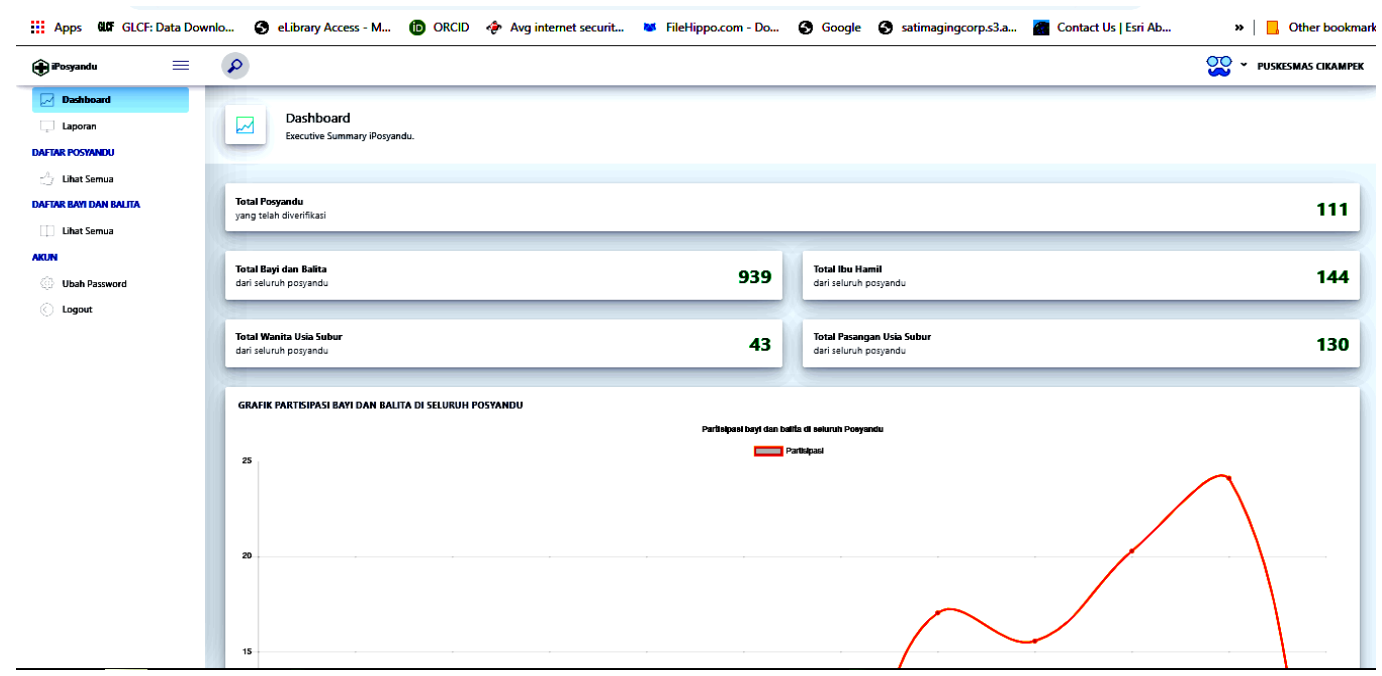

Gambar 1.

Menu Website untuk Puskesmas Cikampek

Adanya situs website untuk mengatasi berbagai permasalahan tentang pengelolaan data. Informasi gizi dipengaruhi oleh kesadaran pentingnya pengelolaan data gizi bagi pihak-pihak yang terlibat. Sistem pengelolaan data yang sering berubah baik metode pelaporan maupun instrumen (format yang tersedia) dan adanya teknologi informasi seperti ketersediaan internet dan program aplikasi database. Proses pengambilan keputusan seringkali tidak didasarkan pada masalah yang ada (evidence based) dan akurasi serta updating data 
yang tersedia membuat keputusan yang diambil seringkali tidak tepat sasaran.(Wirawan et al.)

Berdasarkan tabel 3 di atas, didapatkan bahwa persepsi petugas gizi mengenai informasi dalam situs website sebagian besar setuju, meliputi informasi kontak sebesar 30\%, informasi umum tentang iPosyandu sebesar 27\%, informasi tentang kegiatan iPosyandu sebesar $32 \%$, privasi dalam menemukan informasi yang terkait dengan iPosyandu sebesar 32\%, dan informasi yang terkait dengan pelayanan pelanggan sebesar $30 \%$.

Informasi merupakan penilaian apakah prosedur yang ada saat ini masih dapat diperbaiki sehingga kualitas informasi yang dihasilkan menjadi semakin baik. Kualitas dari suatu informasi tergantung dari 3 hal yaitu informasi harus akurat, tepat pada waktunya, dan relevan. Akurat adalah Informasi harus bebas dari kesalahan-kesalahan dan tidak bias atau menyesatkan. Tepat pada waktu (up to date) adalah informasi yang disampaikan tidak boleh terlambat dan informasi yang ada harus yang terbaru, sedangkan relevan yaitu informasi yang disajikan harus tepat pada sasaran atau berguna bagi pemakainya.(Iqbal and Husin, 2017)

Berdasarkan tabel 4. di atas didapatkan bahwa persepsi petugas gizi terkait tampilan situs website sebagian besar setuju, meliputi situs web terlihat menarik sebesar $41 \%$, situs web terlihat terorganisir sebesar $43 \%$, ketepatan pemilihan ukuran huruf sebesar $55 \%$, ketepatan pemilihan warna sebesar $48 \%$, dan ketepatan menggunakan fitur multimedia sebesar $45 \%$.

Hasil penelitin ini sejalan dengan penelitian yang dilakukan oleh Inasari bahwa desain situs di website cukup atraktif dan waktu loading pembukaan halaman tidak terlalu lama. Dengan demikian, Dinas Kesehatan Surabaya menggunakan website untuk memberikan layanan telemedika yang lebih kompleks dengan forum konsultasi, e-library, wikihealth, peta lokasi sarana kesehatan, data puskesmas, dan informasi kesehatan lainnya. Forum konsultasi tidak digunakan sebagaimana layaknya konsultasi lebih cenderung digunakan sebagai media koordinasi internal dan permintaan data dari pihak luar.(Widyastuti, 2008)

\section{KESIMPULAN}

Dari hasil penelitian dan pembahasan pada bab sebelumnya, didapatkan hasil bahwa persepsi petugas gizi tentang situs website aplikasi iPosyandu sebagian besar setuju, baik mengenai isi, informasi dan tampilan situs website.

\section{SARAN}

Hasil penelitian ini di harapkan website iPosyandu menjadi informasi penting kepada petugas gizi untuk memudahkan pemantauan pelaksanaan pemantaun status gizi di wilayah kerja Puskesmas masing-masing agar bisa cepat dan tepat di tangani apabila terdapat kasus-kasus penyimpangan gizi pada balita di wilayah nya.

\section{DAFTAR PUSTAKA}

Aladwani, A.M. \& Palvia, P.C. ALADWANI, A. M. \& PALVIA, P. C. 2002. Developing and validating an instrument for measuring userperceived web quality. Information \& management, 39, 467-476.

ANESTIS, G., GRIGOROUDIS, E., KRASSADAKI, E., MATSATSINIS, N. F. \& SISKOS, Y. 2006. Skills Evaluator: a multicriteria decision support system for the evaluation of qualifications and skills in Information and Communication Technologies. Journal of Multi-Criteria Decision Analysis, 14, 21-34.

AZIZ, H. 2016. Sistem Informasi Pendataan Kelahiran dan Tumbuh Kembang Bayi Berbasis Web. Fakultas Teknik.

CHIRITA-EMANDI, A., BARBU, C. G., CINTEZA, E. E., CHESARU, B. I., GAFENCU, M., MOCANU, V., PASCANU, I. M., TATAR, S. A., BALGRADEAN, M. \& DOBRE, M. 2016. Overweight and underweight prevalence trends in children from Romania-pooled analysis of cross-sectional studies between 2006 and 2015. Obesity facts, 9, 206-220.

DARELY, P. D. K. \& IQBAL, M. 2019. Perbandingan efektivitas penggunaan database makanan berbasis website, dekstop dan buku pada mahasiswa gizi di Indonesia. AcTion: Aceh Nutrition Journal, 4, 75-80.

http://dikti.go.id/tingkatkan-teknologi-kesehatandemi-kemandirian-produkkesehatan/\#vpFhaZ4y5Mv11rfo.99

IQBAL, M. \& HUSIN, H. 2017. ANALISIS PERBANDINGAN KUALITAS DAN FASILITAS WEB KONSULTASI KESEHATAN DENGAN PENDEKATAN PIECES FRAMEWORK. MIKROTIK: Jurnal Manajemen Informatika, 7, 62-70.

MUJIASTUTI, R., ABDUSSANI, A. \& ADHARANI, Y. 2018. Sistem Pakar Untuk Tumbuh Kembang Anak Menggunakan Metode Forward Chaining. Prosiding Semnastek.

SETYOWATI, M. \& ASTUTI, R. 2015. Pemetaan Status gizi balita dalam mendukung keberhasilan pencapaian millenium 
development goals (MDGs). KEMAS: Jurnal Kesehatan Masyarakat, 10, 110-121.

SUSANTI, A. I., RINAWAN, F. R. \& AMELIA, I. 2019. Mothers Knowledge and Perception of Toddler Growth Monitoring Using iPosyandu Application. Global Medical \& Health Communication, 7, 93-99.

WIDYASTUTI, I. 2008. Analisa Aplikasi E-Health Berbasis Website di Instansi Kesehatan Pemerintah dan Swasta serta Potensi
Implementasinya di Indonesia. Jurnal Penelitian IImu Pengetahuan dan Teknologi Komunikasi, 10.

WIRAWAN, S., ABDI, L. K. \& SULENDRI, N. K. S. PEMANFAATAN DATA DAN INFORMASI SURVEILANS GIZI (wWw. sigizi. com) SEBAGAI BAHAN UNTUK PENGAMBILAN KEPUTUSAN PROGRAM GIZI DI PUSKESMAS SE-KABUPATEN LOMBOK BARAT. 